\title{
An Evaluation of the Relative Merits of Two Methods for Measuring the Balance of Sterols in Man: Isotopic Balance Versus Chromatographic Analysis *
}

\author{
Scott M. Grundy $\dagger$ and E. H. Ahrens, JR. \\ (From the Rockefeller University, New York, N. Y.)
}

In 1957 an isotopic balance method was described (1) for the measurement of excretion products of cholesterol in intact organisms. In this procedure radioactive cholesterol was administered to patients, and radioactivity in feces was subsequently measured, sufficient time being allowed for isotopic equilibrium to be reached between plasma cholesterol and biliary cholesterol and bile acids. On the assumption that the specific activity of fecal excretion products derived from endogenous cholesterol would be the same as that of plasma cholesterol, the mass of fecal neutral and acidic steroids ${ }^{1}$ was estimated from the total radioactivity excreted in those two fractions. The assumption appeared to be validated for the neutral fraction when it was found that specific activities of plasma cholesterol and of fecal neutral steroids were identical on a fat-free regimen. Later it was shown by Lindstedt and Ahrens (2) that the specific activity of bile acids and cholesterol in bile became approximately equal to that of plasma cholesterol.

The first clinical application (1) of this method was made in a patient with hypercholesteremia and carbohydrate-induced hyperglyceridemia $(3 ; 4$, patient H.S.). Substitution of corn oil for butter oil in the diet, each at $40 \%$ of total calories, pro-

* Submitted for publication March 18, 1966; accepted June 9, 1966.

This study was supported in part by U. S. Public Health Service grant HE-06222 from the National Heart Institute, and in part by U. S. Public Health Service grant FR-00102 from the General Clinical Research Centers Branch of the Division of Research Facilities and Resources.

$\dagger$ Address requests for reprints to Dr. Scott M. Grundy, Rockefeller University, New York, N. Y. 10021.

1 The term fecal "steroid" is used in preference to "sterol" because of the significant amounts of ketonic metabolites of cholesterol that invariably are present in neutral and acidic fractions. duced a decrease in plasma cholesterol that was associated with a reciprocal increase in fecal neutral steroids, but not in fecal bile acids. This study in one patient was not reported in detail, but the isotopic balance method has been utilized subsequently by Moore, Anderson, Keys, and Frantz (5) and by Avigan and Steinberg (6) in similarly designed clinical experiments in a total of 11 subjects; they also obtained evidence to support the validity of the assumptions on which the method is based.

Since an analytical technique that depends on in vivo administration of radioisotopes is useful only in certain limited situations, we subsequently devoted considerable effort to the development of sensitive chemical methods for quantitative isolation and measurement of fecal neutral and acidic steroids $(7,8)$. Analysis by a combination of thin layer and gas liquid chromatography (TLC and GLC) has several advantages over the isotopic balance method. It eliminates dependence on use of radioisotopes in patients. It gives a direct measurement of mass of the two steroid fractions yet provides a qualitative as well as quantitative pattern of steroid excretion. Finally, it presents a method for quantitative analysis of fecal conversion products of plant sterols independent from those of cholesterol. The latter is a cardinal feature of the present method, since a measurement of plant sterol balance provides an accurate estimate of the degree of neutral sterol degradation in the course of transit through the intestine; this estimate allows a correction to be made for the degradation of cholesterol and its neutral steroid conversion products.

We have had the opportunity recently to study again the same patient in whom the isotopic balance method was originally used, to compare results obtained by chromatographic and isotopic 
methods applied simultaneously, and to evaluate the advantages of the two techniques. The feeding pattern was almost the same as that used in the first study, but the excretions of fecal steroids were corrected for fecal flow rates by reference to the excretion of the inert marker, chromic oxide, as previously described by Spritz, Ahrens, and Grundy (9), and in addition it was now possible to determine that in this study there was a negligible degree of neutral sterol degradation. The results of this study lend support to previously pre-

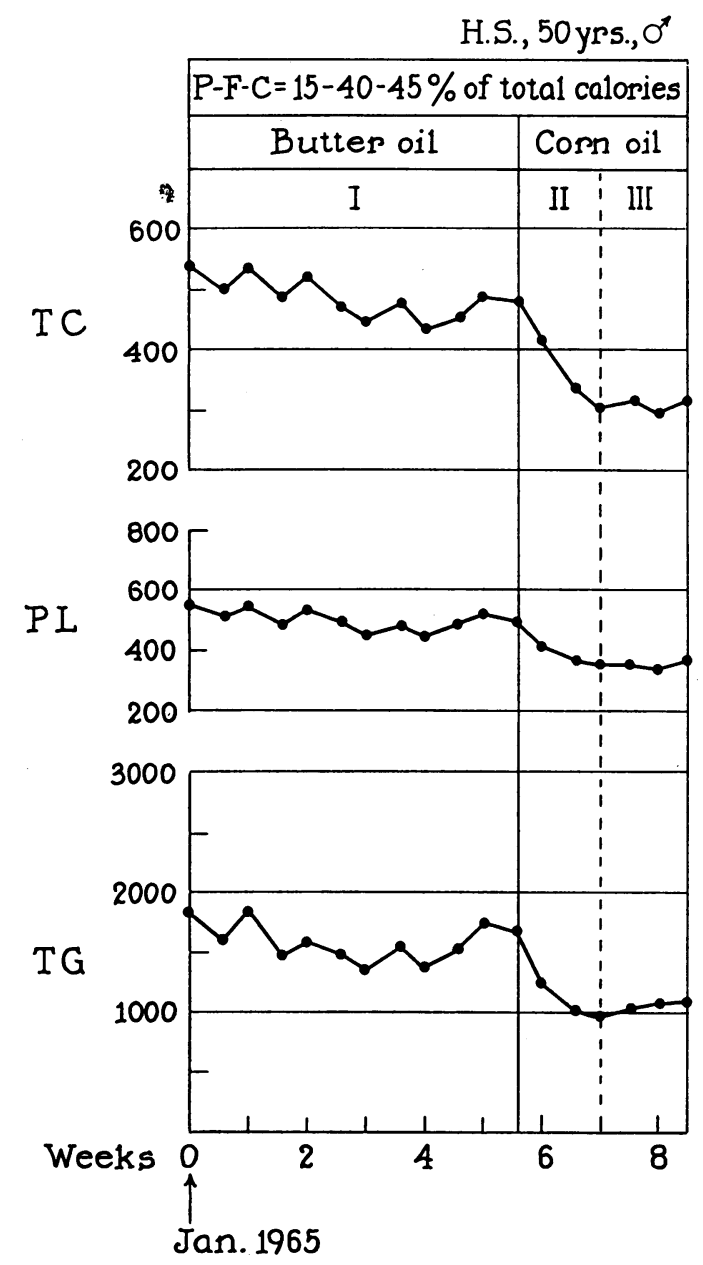

Fig. 1. Decrease in SERUM Lipids AFter SUbStituTION OF CORN OIL FOR BUTTER OIL AT $40 \%$ OF TOTAL CALORIES. Body weight held constant throughout by feeding $31 \mathrm{cal}$ per $\mathrm{kg}$. Period II $=$ transition period between steady states I and III. Cholesterol-4- ${ }^{14} \mathrm{C}(80 \mu \mathrm{c})$ administered intravenously 21 days before day 0 on this chart. TC, total cholesterol; PL, phospholipids; TG, triglycerides, all as $\mathrm{mg}$ per $100 \mathrm{ml}$ serum. $\mathrm{P}-\mathrm{F}-\mathrm{C}=$ protein-fat-carbohydrate. sented evidence that our new analytical methods give quantitative recoveries of fecal bile acids and neutral steroids.

We present also a method for calculating the absorption of exogenous cholesterol, using the data for neutral steroid excretion obtained by combined use of the two sterol balance methods. For the second time in this patient we observed an increased excretion of steroids when corn oil replaced butter in the diet. However, the excretion increment was considerably greater than that needed to explain the decrement in plasma cholesterol content; present evidence suggests a net flux of cholesterol from tissues on the corn oil diet. The markedly increased excretion encountered in this patient is unusual in our experience.

\section{Methods}

\section{Clinical aspects}

H.S., a 50-year-old white male with carbohydrate-induced hyperglyceridemia and hypercholesteremia, was hospitalized on a metabolic ward at the Rockefeller University Hospital for 3 months; the present study relates to the final 9 weeks. During our previous study of him in 1957 he had extensive eruptive and tuberous skin xanthomatosis, but presumably as a consequence of ingesting moderate amounts of unsaturated dietary fat for 8 years the xanthomata had disappeared, even though his total body weight of $79 \mathrm{~kg}$ remained unchanged $(118 \%$ of normal for age, sex, height, and body build, according to life insurance tables 2 ). According to the typing method for hyperlipidemias described by Lees and Fredrickson (10), he falls into type 5 . He has no personal or family history of the complications of atherosclerosis.

His food intake during the present study consisted exclusively of orally administered liquid formula feeding in which protein contributed $15 \%$, fat $40 \%$, and glucose $45 \%$ of total caloric intake; vitamin and mineral supplements were given daily as previously described (11). Total caloric intake was adjusted to avoid weight change; he required $2,440 \mathrm{cal}$ per day (31 cal per $\mathrm{kg}$ body weight). Butter oil and corn oil successively constituted the sole dietary fats. The butter formula provided a daily intake of $300 \mathrm{mg}$ cholesterol and no plant sterols; during the corn oil regimen the sterol intake consisted of $34 \mathrm{mg}$ cholesterol per day (from the milk protein product used as sole dietary protein) and $975 \mathrm{mg}$ mixed plant sterols (175 campesterol, $68 \mathrm{mg}$ stigmasterol, and $732 \mathrm{mg}$ of $\beta$-sitosterol). We made no attempt here to feed the same amount of sterols in the two periods, but chose to repeat the experimental design of the 1957 study as exactly as possible.

2 Values for normal weight related to age, sex, height, and body build were obtained from the Metropolitan Life Insurance Co. 
Figure 1 shows the changes in serum lipid concentrations caused by exchanging corn oil for butter. The 9-week experiment was divided into three periods. The butter feeding period of $5 \frac{1}{2}$ weeks is called period I. When corn oil replaced butter in the diet, plasma lipid concentrations decreased sharply and reached a new plateau at the seventh week. The last period, in which a new steady state on corn oil had been reached, is designated period III ; the transition period ( $5 \frac{1}{2}$ to 7 weeks) is labeled period II. During period I stools were collected in 4-day pools; 1 - or 2-day pools were made during periods II and III, except for a 4-day collection at the end of period III.

Cholesterol-4- ${ }^{14} \mathrm{C}(80 \mu \mathrm{c})$ was administered 21 days before period I began. One $\mathrm{ml}$ of ethanol containing the radioactive tracer was dispersed in $150 \mathrm{ml}$ physiologic saline; the mixture was immediately administered intravenously. A 3-week interval before beginning period I was allowed for crossover of the specific activities of the fecal bile acid and plasma cholesterol pools.

\section{Laboratory methods}

Isolation and gas-liquid chromatographic analysis. Dietary and fecal neutral steroids and fecal acidic steroids were isolated separately and were measured by GLC, as reported elsewhere $(7,8)$. This procedure permits the critical distinction to be made between plant sterols, cholesterol, and all bacterial conversion products derived from these two sources during intestinal transit.

The flow sheet (Figure 2) outlines the main procedural steps (solid lines); for details, the previously cited reports should be consulted $(7,8)$. Neutral steroids were freed from contaminants by TLC, their radioactivity was counted, and their mass was measured by GLC. The acidic steroids were isolated from the petroleum ether-insoluble residue. After a rigorous saponification designed to hydrolyze bile acids still present in conjugated form, the free bile acids were extracted with chloroform-methanol and chloroform. The bile acids were methylated, then separated from the bulk of fatty acids and acidic pigment contaminants by TLC. The radioactivity of this fraction was counted, and the mass of acidic steroids was measured by GLC.

Radioactivity was measured by means of a Packard Tri-Carb scintillation spectrometer (model 3003) as previously described (7). Toluene- ${ }^{14} \mathrm{C}$ was used as internal standard to correct for quenching.

Isotopic balance method (hereafter referred to as the isotopic method). Total radioactivity in the fecal neutral and acidic steroid fractions was measured after extraction and separation as designated in Figure 2 (dashed lines). These values were converted to steroid mass by relating them to the specific activity of plasma cholesterol, with values extrapolated from the isotopic die-away curve. The mass of plasma cholesterol was measured by the method of Abell, Levy, Brodie, and Kendall (12); its radioactivity was measured on a sample of the same extract used for spectrophotometry. Neutral and acidic steroid masses were calculated as follows: Fecal steroid excretion (milligrams per day) = total radioactivity in

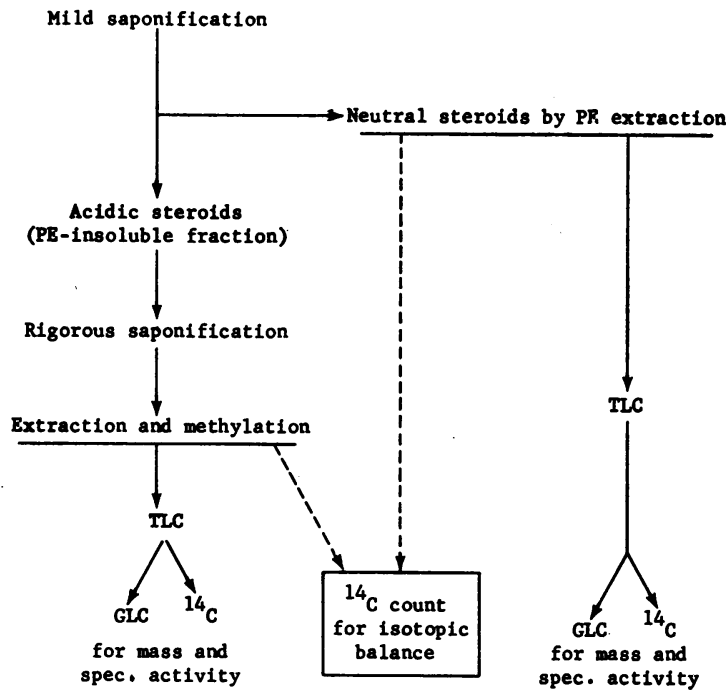

Fig. 2. Flow SHEET FOR DETERMination OF FECAL NEUTRAL AND ACIDIC STEROIDS BY CHEMICAL ISOLATION FOLLOWED BY GAS-LIQUID CHROMATOGRAPHY (GLC), AND BY ISOTOPIC BALANCE METHOD. Samples taken for the latter method are shown in dashed lines. Details of GLC method have been published $(7,8)$. TLC, thin layer chromatography; $\mathrm{PE}=$ petroleum ether.

fraction (disintegrations per minute per day)/specific activity of plasma cholesterol (disintegrations per minute per milligram) 1 to 2 days previously (see below).

Corrections for fecal flow. With the isotopic method, calculations of mass of neutral and acidic steroids were based on the specific activity of plasma cholesterol on the second day of 4-day stool collections and on the day preceding the collection of 1- and 2-day pools. The assumption that intestinal contents passed completely through the intestine in 1 day was made also in the previous studies of Moore and associates (5) and of Avigan and Steinberg (6).

Steroid excretions measured by both GLC and isotopic methods were corrected for actual fecal flow rates by reference to the excretion of an inert material administered orally as an internal standard. Chromic oxide $\left(\mathrm{Cr}_{2} \mathrm{O}_{3}\right)$ was used for this purpose and measured as described by Whitby and Lang (13) and Stanley and Cheng (14) after sulfuric acid-perchloric acid digestion. This correction for variability in colonic emptying is particularly important when stool collections are made for short periods, as in periods II and III. The patient received a $60-\mathrm{mg}$ tablet of finely ground $\mathrm{Cr}_{2} \mathrm{O}_{3}$ with each of his five daily formula feedings throughout the study. Excretions were corrected for fecal flow rates as follows: Daily excretion of acidic or neutral fecal steroids (milligrams), corrected for fecal flow $=$ [daily intake of $\mathrm{Cr}_{2} \mathrm{O}_{3}$ (milligrams)/milligrams $\mathrm{Cr}_{2} \mathrm{O}_{3}$ per gram of fecal homogenate] $\times$ (milligrams of fecal steroids/grams of fecal homogenate).

Correction for sterol degradation. The extent of neutral sterol degradation during intestinal transit was esti- 
mated by comparing the daily intake of total plant sterols to the recovery of all neutral steroids derived from plant sterols. Gould, Lotz, and Lilly (15) found that only $4 \%$ of a $50-\mathrm{mg}$ dose of labeled $\beta$-sitosterol was absorbed in tests carried out in five patients. Therefore, it is evident that excretion of plant sterols will approximate intake when the diet habitually contains considerable amounts of plant sterols. In studies as yet unpublished we have found that the degradation of cholesterol and of plant sterols is precisely the same; thus, the excretion of neutral cholesterol products can be accurately corrected for degradative losses according to the percentage recovery of plant sterols, as follows: Daily excretion of fecal steroids (milligrams), corrected for degradative losses = daily excretion of steroids (milligrams)/per cent recovery of plant sterol. When this correction is applied, it is unnecessary to correct for fecal flow by $\mathrm{Cr}_{2} \mathrm{O}_{3}$, since the recovery of plant sterols automatically serves this purpose as well as correcting for sterol degradation.

Acidic steroid degradation also occurs, but in our experience to date it has never exceeded the degree of degradation of the neutral steroids. Until a direct method for estimating this degradation is found, we have chosen to apply the formula given above to the acidic as well as the neutral steroids, recognizing that the errors in absolute terms are relatively small and that the application of this formula is preferable to overlooking the question completely.

\section{Results}

The major objective of this study was to compare the relative advantages of the isotopic and GLC methods for measurement of sterol balances in man, and on the basis of this to suggest how best to accomplish such balance studies in future efforts to explore problems of absorption, synthesis, feedback control, and transfer to tissues. In addition, the present study allowed us to investigate two other questions: 1) Does fecal steroid excretion increase to balance the decrease in plasma cholesterol when corn oil is substituted for butter oil in the diet, as previously demonstrated

TABLE I

Daily fecal steroid excretion measured by isotopic and GLC methods during periods $I, I I$, and III, corrected for fecal flow rates

\begin{tabular}{|c|c|c|c|c|c|c|c|}
\hline \multirow[b]{3}{*}{ Period } & \multirow{3}{*}{$\begin{array}{c}\text { Days after } \\
\text { cholesterol-4-14C } \\
\text { administration }\end{array}$} & \multicolumn{6}{|c|}{ Daily fecal steroid excretion } \\
\hline & & \multicolumn{2}{|c|}{ Acidic steroids } & \multicolumn{2}{|c|}{ Neutral steroids } & \multicolumn{2}{|c|}{ Total steroids } \\
\hline & & Isotopic* & $\overline{\mathrm{GLC}} \dagger$ & Isotopic* & $\overline{\text { GLC } †}$ & Isotopic* & $\overline{\text { GLC } \dagger}$ \\
\hline & & \multicolumn{6}{|c|}{$m g / d a y$} \\
\hline $\begin{array}{l}\text { I } \\
\text { (butter, } \\
\text { steady state) }\end{array}$ & $\begin{array}{l}21-24 \\
25-28 \\
29-32 \\
33-36 \\
37-40 \\
41-44 \\
45-48 \\
49-52 \\
53-56 \\
57-60\end{array}$ & $\begin{array}{r}1,070 \\
1,030 \\
750 \\
880 \\
795 \\
1,096 \\
1,290 \\
735 \\
1,100 \\
955\end{array}$ & $\begin{array}{r}812 \\
709 \\
575 \\
653 \\
555 \\
945 \\
1,221 \\
640 \\
1,010 \\
865\end{array}$ & $\begin{array}{r}826 \\
613 \\
600 \\
703 \\
612 \\
864 \\
1,080 \\
624 \\
667 \\
565\end{array}$ & $\begin{array}{r}1,023 \\
802 \\
650 \\
973 \\
720 \\
1,122 \\
1,390 \\
760 \\
910 \\
725\end{array}$ & $\begin{array}{l}1,896 \\
1,643 \\
1,350 \\
1,583 \\
1,407 \\
1,960 \\
2,370 \\
1,359 \\
1,767 \\
1,510\end{array}$ & $\begin{array}{l}1,835 \\
1,511 \\
1,225 \\
1,626 \\
1,275 \\
2,067 \\
2,611 \\
1,400 \\
1,920 \\
1,590\end{array}$ \\
\hline $\begin{array}{l}\text { II } \\
\text { (transition on } \\
\text { corn oil) }\end{array}$ & $\begin{array}{l}61 \\
63 \\
65 \\
67 \\
68 \\
69 \\
70 \\
71\end{array}$ & $\begin{array}{r}970 \\
806 \\
900 \\
1,069 \\
1,650 \\
1,250 \\
1,440 \\
1,281\end{array}$ & $\begin{array}{r}915 \\
683 \\
656 \\
983 \\
1,410 \\
1,130 \\
1,442 \\
1,205\end{array}$ & $\begin{array}{r}665 \\
583 \\
838 \\
1,175 \\
1,041 \\
1,055 \\
1,318 \\
1,121\end{array}$ & $\begin{array}{r}825 \\
575 \\
772 \\
1,118 \\
1,041 \\
1,090 \\
1,355 \\
1,121\end{array}$ & $\begin{array}{l}1,635 \\
1,389 \\
1,738 \\
2,244 \\
2,691 \\
2,305 \\
2,758 \\
2,402\end{array}$ & $\begin{array}{l}1,740 \\
1,258 \\
1,428 \\
2,101 \\
2,451 \\
2,220 \\
2,897 \\
2,326\end{array}$ \\
\hline $\begin{array}{l}\text { III } \\
\text { (corn oil, } \\
\text { steady state) }\end{array}$ & $\begin{array}{c}73 \\
74 \\
75 \\
76 \\
78 \\
79 \\
80-83\end{array}$ & $\begin{array}{r}1,010 \\
1,540 \\
1,840 \\
740 \\
1,275 \\
1,790 \\
860\end{array}$ & $\begin{array}{r}938 \\
1,450 \\
2,050 \\
750 \\
1,275 \\
1,790 \\
1,185\end{array}$ & $\begin{array}{r}1,150 \\
1,540 \\
1,370 \\
875 \\
1,180 \\
1,231 \\
920\end{array}$ & $\begin{array}{r}1,112 \\
1,450 \\
1,391 \\
892 \\
1,160 \\
1,129 \\
985\end{array}$ & $\begin{array}{l}2,160 \\
3,080 \\
3,210 \\
1,615 \\
2,455 \\
3,021 \\
1,780\end{array}$ & $\begin{array}{l}2,050 \\
2,900 \\
2,441 \\
1,642 \\
2,435 \\
2,914 \\
2,170\end{array}$ \\
\hline
\end{tabular}

* Isotopic balance method [corrected for fecal flow by chromic oxide (9)]: milligrams of steroid=disintegrations per minute in fecal steroid fraction/specific activity of plasma cholesterol on second day of 4-day stool collections or on day preceding 1-day collections.

$\dagger$ Isolation of steroids and measurement by gas-liquid chromatography $(\mathrm{GLC})(7,8)$, corrected for fecal flow by chromic oxide (9). 
in this patient by the isotopic method? 2) Can absorption of exogenous cholesterol be measured in a patient receiving $300 \mathrm{mg}$ per day of dietary cholesterol by combining the data obtained by the two steroid balance methods?

\section{Estimate of sterol degradation}

Plant sterols were ingested only during the corn oil regimen, periods. II and III ( 22 days in duration). In the last 15 days of that regimen, the daily intake of plant sterols was $975 \mathrm{mg}$, and the amount recovered in the feces averaged $929 \mathrm{mg}$ per day. In view of this high percentage recovery (95.3\%) of plant sterols, it was unnecessary to correct the fecal steroid data in periods II and III for degradative losses. In the same period the recovery of $\mathrm{Cr}_{2} \mathrm{O}_{3}$ was $100.7 \%$, indicating that corrections for fecal flow with this marker were valid. During period I we had no way to measure possible losses of cholesterol products through degradation, since the diet was free of plant sterols. However, on the basis of the nearly perfect recovery $(97.7 \%)$ of $\mathrm{Cr}_{2} \mathrm{O}_{3}$ during the 63 days of periods I + II + III, and in view of the $95 \%$ recovery of plant sterols in periods II + III, we assumed that sterol losses through degradation in period I were negligible.

\section{Daily fecal steroid excretion}

Excretions of acidic and neutral fecal steroids during periods I, II, and III are presented in detail in Table I and Figure 3 and summarized in

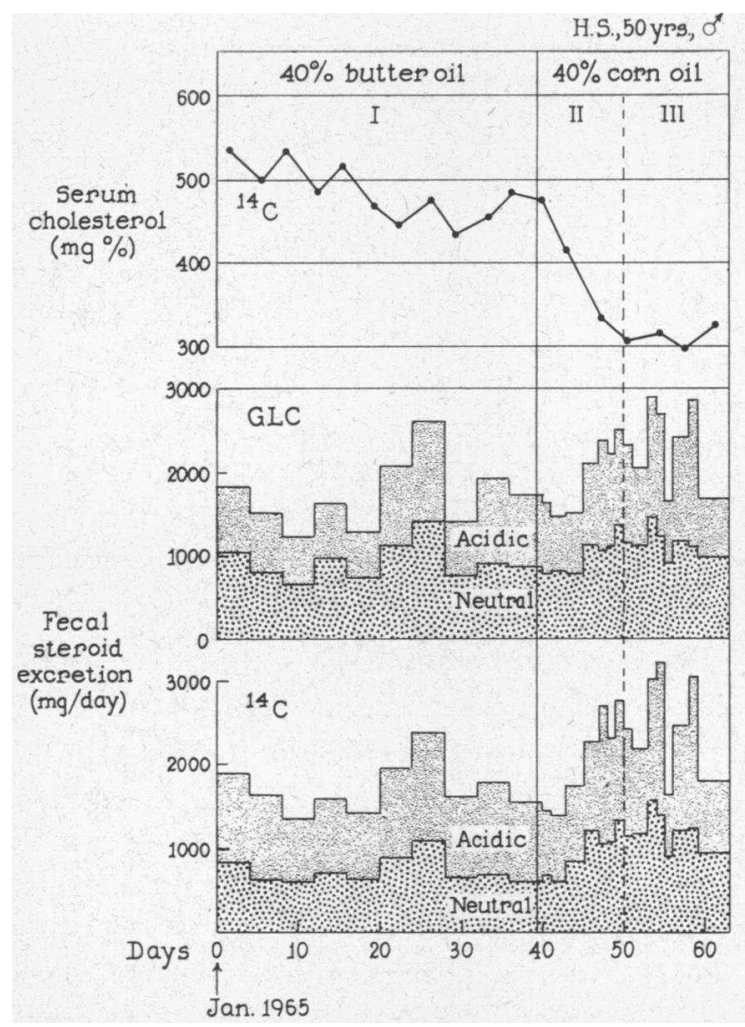

Fig. 3. RELATIONSHip BETWEen FECAL STERoId EXCRETION, MEASURED BY GLC AND ISOTOPIC METHODS, AND CHANGES IN SERUM CHOLESTEROL CONCENTRATIONS (WHEN CORN OIL REPLACED BUTTER IN THE DIET AT $40 \%$ OF TOTAL CALORIES). Note that there was no striking change in excretion during period II, but the total excretion in periods II + III significantly exceeded that in period I (by both methods). (Cholesterol- $4-{ }^{14} \mathrm{C}$ administered 21 days before day 0 on this chart.)

TABLE II

Average daily fecal steroid excretion when butter oil, then corn oil constituted $40 \%$ of total calories

\begin{tabular}{|c|c|c|c|c|c|c|c|c|}
\hline \multirow[b]{3}{*}{ Period } & \multirow[b]{3}{*}{ Days } & \multirow{3}{*}{$\begin{array}{l}\text { No. of } \\
\text { stool } \\
\text { collections }\end{array}$} & \multicolumn{6}{|c|}{ Daily fecal steriod excretion $\pm S D$} \\
\hline & & & \multicolumn{2}{|c|}{ Acidic steroids } & \multicolumn{2}{|c|}{ Neutral steroids } & \multicolumn{2}{|c|}{ Total steroids } \\
\hline & & & Isotopic* & GLC† & Isotopic* & GLC† & Isotopic* & GLC $†$ \\
\hline & & & \multicolumn{6}{|c|}{$m g / d a y$} \\
\hline $\begin{array}{l}\text { I } \\
\text { (butter, } \\
\text { steady state) }\end{array}$ & 40 & 10 & $\begin{array}{r}970 \\
\pm 180\end{array}$ & $\begin{array}{r}799 \\
\pm 212\end{array}$ & $\begin{array}{r}715 \\
\pm 161\end{array}$ & $\begin{array}{r}908 \\
\pm 226\end{array}$ & $\begin{array}{l}1,685 \\
\pm 320\end{array}$ & $\begin{array}{l}1,707 \\
\pm 418\end{array}$ \\
\hline $\begin{array}{l}\text { II } \\
\text { (transition } \\
\text { on corn oil) }\end{array}$ & 10 & 8 & $\begin{array}{l}1,170 \\
\pm 287 \\
\text { NSt }\end{array}$ & $\begin{array}{l}1,053 \\
\pm 299 \\
\text { NS }\end{array}$ & $\begin{aligned} & 975 \\
&+ 255 \\
& \mathrm{NS}\end{aligned}$ & $\begin{aligned} & 987 \\
& \pm 246 \\
& \mathrm{NS}\end{aligned}$ & $\begin{array}{l}2,145 \\
\pm 503 \\
\text { NS }\end{array}$ & $\begin{array}{l}2,040 \\
\pm 545 \\
\text { NS }\end{array}$ \\
\hline $\begin{array}{l}\text { II + III } \\
\text { (corn oil, transitior } \\
\text { and steady state) }\end{array}$ & 24 & 15 & $\begin{array}{l}1,227 \\
\quad \stackrel{ \pm 62}{<} 0.058\end{array}$ & $\begin{array}{c}1,191 \\
\pm 398 \\
\mathrm{p}<0.01\end{array}$ & $\begin{array}{c}1,071 \\
\stackrel{ \pm}{ \pm} 262 \\
\mathrm{p} 0.001\end{array}$ & $\begin{array}{l}1,067 \\
\pm 236 \\
\mathrm{NS}\end{array}$ & $\begin{aligned} & 2,298 \\
& \pm 580 \\
\mathrm{p} & <0.005\end{aligned}$ & $\begin{array}{l}2,258 \\
\quad \stackrel{ \pm}{ \pm}=0.025\end{array}$ \\
\hline
\end{tabular}

*, + See corresponding footnotes to Table I.

I Statistically not significant, as compared to period $\mathrm{I}$, where $\mathrm{n}$ in Student's $t$ test $=$ number of stool collections.

$\$$ Difference from period I statistically significant, at stated p level, where $n$ in Student's $t$ test $=$ number of stool collections. 


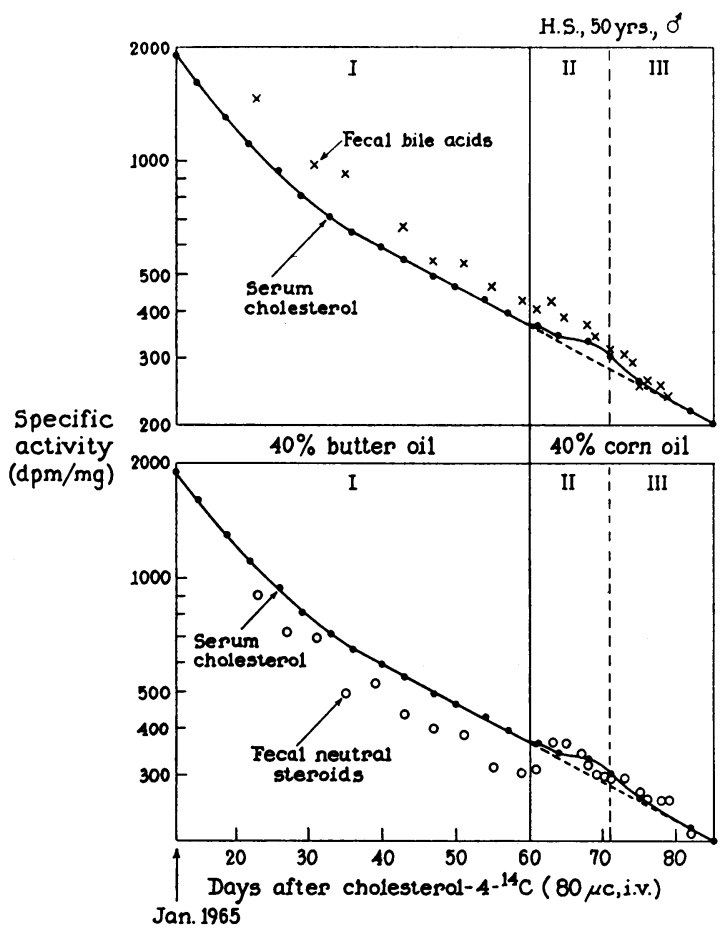

Fig. 4. Specific activity time CURve for Serum CHOLESTEROL, FECAL BILE ACIDS, AND FECAL NEUTRAL STEROIDS DURING BUTTER AND CORN OIL FEEDING PERIODS. MasS of serum cholesterol determined by Liebermann-Burchard reaction (12) and of fecal steroids by isolation and GLC $(7,8)$. Periods I, II, and III correspond to those shown in Figure 1.

Table II. The term "fecal neutral steroids" in this paper refers to neutral steroids of all types $\left(\Delta^{5}, 5 \alpha\right.$, and $\left.5 \beta\right)$ when the dietary sterol is solely cholesterol ; when the diet also contains plant sterols, the term refers only to the neutral steroids derived from cholesterol.

Acidic steroids. During period I the excretion of acidic steroids measured by the isotopic method averaged $970 \mathrm{mg}$ per day, whereas that measured by the GLC method was $799 \mathrm{mg}$ per day (a difference of $21 \%$ ). The difference in results of the two methods decreased to $11 \%$ in period II and to $6 \%$ in periods II + III.

We believe that the differences in the results obtained for acidic steroids by the two methods are inherent in the two methods used and that the higher figures obtained by the isotopic method are due to the kinetics resulting from the precursorproduct relationship between cholesterol and bile acids. Figure 4 (upper) shows specific activity- time curves of plasma cholesterol and of fecal bile acids. The specific activity of fecal bile acids was higher than that of plasma cholesterol at 25 days when the first measurement was made; the crossover of product and precursor described by Zilversmit (16) had taken place earlier. The degree of this difference is determined by the pool sizes and turnover rates of the cholesterol and bile acid pools; the larger the bile acid pool (or the smaller the cholesterol pool) and the slower the turnover of bile acids (or the faster the turnover of cholesterol), the greater the difference between the two specific activities. The degree of difference steadily decreased during periods II and III, so that from 69 to 79 days after isotopic administration the specific activities of serum cholesterol and fecal neutral and acidic steroids were nearly the same (Table III). The narrowing of differences at the end of the experiment suggests that the increased excretion of acidic steroids in these periods was associated either with a smaller pool size of bile acids or an increase in their turnover rate.

We believe that the numerical results displayed in Tables I and II for bile acid excretion in periods I and II arrived at by the isotopic method are falsely high and that only in period III was it valid to calculate the excretion of fecal acidic steroids by the isotopic method directly, without use of arbitrarily chosen correction factors. The results ob-

TABLE III

Comparison of serum and fecal steroid specific activities during periods $I I$ and $I I I^{*}$

\begin{tabular}{cccc}
\hline \multirow{2}{*}{$\begin{array}{c}\text { Days after } \\
\text { cholesterol- } \\
\text { 4-14C } \\
\text { administration }\end{array}$} & $\begin{array}{c}\text { Serum } \\
\text { cholesterol }\end{array}$ & \multicolumn{2}{c}{ Fecal steroids } \\
\cline { 3 - 4 } & Neutral & Acidic \\
\hline 69 & $3 p m / m g \dagger$ & \multicolumn{2}{c}{$d p m / m g \ddagger$} \\
70 & 334 & 300 & 344 \\
71 & 324 & 298 & 304 \\
73 & 303 & 296 & 314 \\
74 & 290 & 295 & 307 \\
75 & 280 & 266 & 292 \\
76 & 270 & 260 & 262 \\
78 & 260 & 258 & 252 \\
79 & 252 & 260 & 238 \\
& & & \\
\hline
\end{tabular}

* Dietary cholesterol intake $=34 \mathrm{mg}$ per day.

+ Mass measurements by Liebermann-Burchard reaction, according to Abell and associates (12); specific activities extrapolated from data plotted in Figure 4.

$\ddagger$ Mass measurement by GLC after multistep isolation $(7,8)$; data pertain to the day designated, without correction for fecal flow. 
tained by the GLC method, on the other hand, needed only to be corrected for fecal flow rates.

Statistical analysis of the results obtained by the GLC method showed a significantly higher excretion in periods II + III than in period I $(p<$ 0.01 by Student's $t$ test). A similar comparison of results obtained by the isotopic method also showed an increased excretion in periods II + III, but at a lower level of significance $(0.01<\mathrm{p}<$ $0.05)$. It should be noted that a significant change in acidic steroid excretion could not be detected by either method during the transition period (II) compared to period I, at the time when plasma cholesterol concentrations were actually decreasing, as Figure 3 clearly shows.

Neutral steroids. During period I the average excretion of neutral steroids measured by the GLC method (908 mg per day, Table II) was approximately $27 \%$ higher than that obtained by the isotopic technique (715 $\mathrm{mg}$ per day), whereas in periods II and II + III averages of excretions determined by the two methods were almost identical (987 vs. 975 , and 1,067 vs. 1,071 , respectively). The explanation for the different results obtained by the two methods in period $I$ is that the butter diet contained cholesterol, whereas in periods II and III the diet was cholesterol free. Thus, as seen in Figure 4 (lower), the specific activity of fecal neutral steroids during period I was consistently lower than that of plasma cholesterol, due to dilution with unabsorbed dietary cholesterol. In other words, in period I the isotopic method estimated only the fecal neutral steroids of endogenous origin, whereas the GLC method measured these but also the unabsorbed dietary cholesterol. When the diet was cholesterol free, both methods measured only the steroids of endogenous origin; thus in periods II and III similar excretion data were obtained by the two methods.

In comparing fecal excretions of neutral steroids in periods I, II, and III, when exogenous cholesterol was offered only during period I, it seems valid to restrict the comparison to the excretions of neutral steroids of endogenous origin. For this purpose the isotopic method seems ideal. As shown in Table II the excretion was significantly higher $(p<0.001)$ during periods II + III than in period I. However, during the transitional period II, when plasma cholesterol levels were actually falling, a significant increase in neutral steroid excretion was not obtained.

Total steroids of endogenous origin. For the reasons described above, we have leaned in this experiment on the GLC method for assessing excretions of the acidic steroids and on the isotopic method for measurements of neutral steroids of endogenous origin. When these two sets of data were combined to give a measure of average total fecal steroid excretion in the three periods (Table IV), we found a $748 \mathrm{mg}$ per day higher excretion of total steroids during periods II + III on the corn oil regimen $(p<0.01)$. The average daily

TABLE IV

Decrement in plasma cholesterol content compared to increment in fecal steroid excretion when corn oil replaced butter in the diet

I. Increment in daily fecal steroid excretion \pm SD

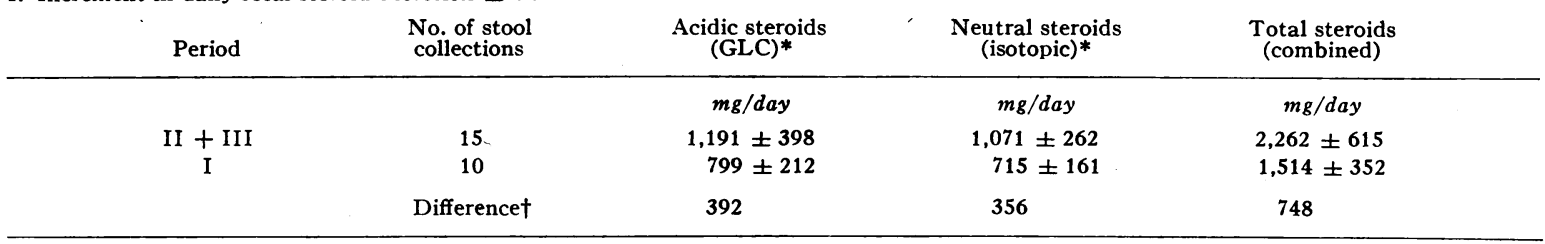

II. Decrement in plasma cholesterol content

\begin{tabular}{|c|c|c|c|c|c|c|}
\hline \multirow{2}{*}{ Body wt } & \multirow{2}{*}{$\begin{array}{c}\text { Estimated } \\
\text { plasma } \\
\text { volume }\end{array}$} & \multicolumn{2}{|c|}{$\begin{array}{l}\text { Plasma cholesterol concentration } \\
\text { (mean } \pm \text { SD) }\end{array}$} & \multirow{2}{*}{$\begin{array}{c}\text { Decrease } \\
\text { in plasma } \\
\text { cholesterol } \\
\text { content }\end{array}$} & \multirow{2}{*}{$\begin{array}{l}\text { Duration } \\
\text { of period } \\
\text { II }+ \text { III }\end{array}$} & \multirow{2}{*}{$\begin{array}{c}\text { Mean daily } \\
\text { plasma cho- } \\
\text { lesterol } \\
\text { decrease }\end{array}$} \\
\hline & & Period I & III & & & \\
\hline $\mathrm{kg}$ & $m l$ & \multicolumn{2}{|c|}{$m g / 100 \mathrm{ml}$} & $m g$ & days & $m g / d a y$ \\
\hline 79 & 3,550 & $461 \pm 19.3$ & $308+11.7$ & 5,450 & 24 & 227 \\
\hline
\end{tabular}

* As described in footnotes to Table $I$.

+ All differences significant $(\mathrm{p}<0.01$ ), where $\mathrm{n}$ in Student's $t$ test $=$ number of stool collections.

$\$ 4.5 \%$ of total body weight (17). 
total steroid excretion of $2,028 \mathrm{mg}$ in period II was not significantly different from that of 1,514 $\mathrm{mg}$ in period $\mathrm{I}$.

\section{Reciprocal changes in plasma cholesterol and fecal steroid excretion}

The magnitude of the change in plasma cholesterol content during period II, when corn oil replaced butter in the diet, is presented in Table IV. A decrease of $545 \mathrm{mg}$ per day in plasma cholesterol content occurred during the 10 days of period II, while at the same time total fecal steroid excretion increased by $514 \mathrm{mg}$ per day. However, inspection of Figure 3 shows that the increased excretion in periods II and III was continuous and not separable. Thus, in view of the lag in excretion shown in Figure 3, it is reasonable to equate the plasma cholesterol decrement in period II with the fecal steroid increment in periods II + III. It is noteworthy that Moore and associates (5) and Avigan and Steinberg (6) considered their data in this manner.

Table IV shows that a decrease of $227 \mathrm{mg}$ per day in plasma cholesterol content occurred during the 24 days of periods II + III, while at the same time total fecal steroid excretion increased by 748 $\mathrm{mg}$ per day. During the corn oil regimen the acidic steroid excretion increased by $49 \%$, endogenous neutral steroids by $50 \%$.

\section{Cholesterol absorption}

Absorption of exogenous cholesterol was calculated from the difference between the two measurements of daily fecal neutral steroid excretion as follows: Exogenous cholesterol absorbed = intake - unabsorbed (milligrams per day). Unabsorbed $=$ fecal neutral steroids $_{\mathrm{GLC}}-$ fecal neutral steroids $s_{\text {isotopic. }}$ The second formula is based on the fact that fecal neutral steroids obtained by the GLC method represented steroids formed from unabsorbed exogenous cholesterol plus endogenous cholesterol, whereas the isotopic method measured only the fecal neutral steroids of endogenous origin. "Fecal neutral steroids $\mathbf{G L C}_{\mathbf{L C}}$ " as calculated from the second equation, refers to all neutral steroids when the dietary sterol is solely cholesterol; when the diet also contains plant sterols, the expression "fecal neutral steroids ${ }_{\mathrm{GLC}}$ " refers only to the neutral steroids derived from cholesterol.
Table $\mathrm{V}$ lists the absolute and percentage absorption of exogenous cholesterol in five successive 8-day fecal pools, each corrected for fecal flow by the $\mathrm{Cr}_{2} \mathrm{O}_{3}$ method. These measurements were made during the last 40 days of the butter regimen, when the formula ingested contained a total of $300 \mathrm{mg}$ of cholesterol per day. Although the intake of cholesterol was low, absorption averaged only $36 \%$; the range of values was small, from 27 to $47 \%$.

\section{Discussion}

Comparison of two methods. The isotopic method is technically simpler than the GLC method and can serve a variety of purposes in clinical investigations of sterol metabolism, if certain precautions are taken. 1) Considerable time must elapse between administration of isotope and measurement of labeled products in the feces. In five formula-fed patients the crossover of the curves of plasma cholesterol and fecal bile acid specific activity occurred between 1 and 3 weeks (9); however, the relationship between the curves does not appear to be constant until 4 to 6 weeks, after which isotopic equilibrium among the various miscible pools of cholesterol has been reached (18, 19). 2) The application of arbitrary time corrections for equating plasma cholesterol and fecal steroid specific activities must be recognized to be risky. From patient to patient, and even from time to time in any one patient, this correction can be expected to vary considerably, depending on speed and completeness of colonic emptying as well as on the varying turnovers of cholesterol and bile acid pools. 3) Some assurance must be obtained of the absence of sterol degradation during intestinal transit, or measurements must be made of the extent of degradation. Excretion data based on recovery of isotopically labeled cholesterol products in the feces will be underestimated whenever sterol degradation occurs. This factor has not been considered in previous studies of sterol balances (tabulated in references 7 and 8).

The GLC method is more laborious, but it offers advantages that in most circumstances outweigh its drawbacks. 1) It does not depend on in vivo administration of radioisotopes. Thus, it can be applied in all members of the populationnormal volunteers, young adults, and children—in 
TABLE V

Serial measurements of cholesterol absorption during period I (butter diet) with cholesterol intake of $300 \mathrm{mg}$ per day

\begin{tabular}{|c|c|c|c|c|c|c|}
\hline \multirow[b]{2}{*}{$\begin{array}{l}\text { Serial stool } \\
\text { collections* } \\
\text { (8 days each) }\end{array}$} & \multicolumn{3}{|c|}{ Fecal neutral steroids } & \multirow[b]{2}{*}{$\begin{array}{c}\text { Cholesterol } \\
\text { intake }\end{array}$} & \multirow[b]{2}{*}{$\begin{array}{c}\text { Cholesterol } \\
\text { absorbed }\end{array}$} & \multirow[b]{2}{*}{$\begin{array}{c}\text { Per cent } \\
\text { absorption } \\
\text { of exogenous } \\
\text { cholesterol }\end{array}$} \\
\hline & $\begin{array}{c}\text { Endogenous } \\
\text { plus un- } \\
\text { absorbed } \\
\text { exogenous } \\
\text { (GLC method) } \dagger\end{array}$ & $\begin{array}{l}\text { Endog- } \\
\text { enous } \\
\text { only } \\
\text { (isotopic } \\
\dagger \text { method) } \dagger\end{array}$ & $\begin{array}{l}\text { Unabsorbed } \\
\text { exogenous } \\
\text { (GLC- } \\
\text { isotopic) }\end{array}$ & & & \\
\hline & $m g / d a y$ & $m g / d a y$ & $m g / d a y$ & $m g / d a y$ & $m g / d a y$ & \\
\hline $\begin{array}{l}1 \\
2 \\
3 \\
4 \\
5\end{array}$ & $\begin{array}{r}913 \\
812 \\
921 \\
1,075 \\
818\end{array}$ & $\begin{array}{l}720 \\
652 \\
738 \\
852 \\
616\end{array}$ & $\begin{array}{l}193 \\
160 \\
183 \\
223 \\
202\end{array}$ & $\begin{array}{l}300 \\
300 \\
300 \\
300 \\
300\end{array}$ & $\begin{array}{r}107 \\
140 \\
117 \\
77 \\
98\end{array}$ & $\begin{array}{l}35.2 \\
46.7 \\
39.1 \\
26.8 \\
32.6\end{array}$ \\
\hline Mean & 908 & 716 & 192 & 300 & 108 & 36.1 \\
\hline
\end{tabular}

* Starting 20 days after administration of cholesterol-4- ${ }^{14} \mathrm{C}$ and ending on the sixtieth day at the termination of period I.

† Calculated as described in footnote to Table I ; fecal steroid radioactivity related to fourth day of each 8-day stool collection.

whom it might be hazardous to administer radioactive compounds. When cholesterol-free diets are fed, the daily total fecal steroid excretion will closely approximate the daily synthesis of cholesterol. 2) Where it is feasible to administer radioisotopes in vivo, use of labeled compounds can be reserved for exploration of important dynamic problems, such as absorption, synthesis, feedback control, and excretory pathways. 3) The GLC method applied to analysis of diets clearly distinguishes plant sterols from cholesterol, as it does to their bacterial conversion products measured in the feces. This permits an accurate measurement of plant sterol balance to be made, so as to assess the degree of sterol degradation during intestinal transit. With this correction factor in hand, the true excretion of cholesterol products can be measured accurately, since cholesterol is degraded to the same degree as plant sterols.

When either method of measuring steroid balances is applied, it is highly desirable to correct calendar stool collections for the rate of fecal flow by incorporation of a readily recognized internal standard in the diet. Chromic oxide has been used in the present study, but in studies not yet published we have obtained evidence that it is not an ideal standard for all patients. It appears that dietary plant sterols are more nearly ideal as internal standards for measurement of cholesterol excretion products. Indeed, with regard to neutral steroids derived from cholesterol, the plant sterols and their conversion products have the same dis- tribution in the intestinal contents and suffer the same degree of destruction. Furthermore, they are measured in the same GLC analysis as the cholesterol products, so that no additional technical work is required to obtain accurate measures of their quantities.

Comparison of the results obtained by the two methods (Tables I and II), especially during periods II and III, lends strong support to our previous evidence $(7,8)$ that the GLC method achieves quantitative measurement of fecal acidic and neutral steroids. The close correspondence of excretion results obtained by the two methods during periods II and III indicates that recovery of fecal steroids during the multistep isolation was quantitative and correctly estimated by GLC analysis. Table III shows how closely the specific activities of the three fractions (serum cholesterol and fecal neutral and fecal acidic steroids) coincided at the end of period III; this could have occurred only if the measurements of fecal steroids, isotopically and by GLC, were as dependable as the mass measurement of serum cholesterol by the Liebermann-Burchard reaction. We consider that the assembled data of Tables I, II, and III strongly support the validity of both sterol balance techniques when the precautions noted above are heeded.

It is evident that more useful information is obtained by applying both methods simultaneously than by using either alone. In experiments based on cholesterol-free diets, the GLC method can 


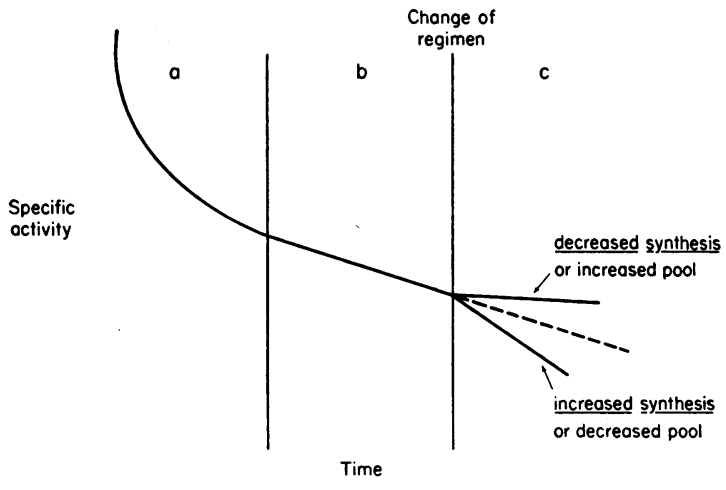

Fig. 5. Schematic log specific activity-time curve FOR SERUM CHOLESTEROL AFTER ADMINISTRATION OF A SINGLE IV DOSE OF RADIOACTIVE CHOLESTEROL. $a=$ period of rapid decay (nonlinear fall-off) ; $b=$ period of isotopic equilibrium between readily miscible pools (linear fall-off) ; $c=$ after change of regimen. In this experimental model the "pool" is conceived of as all the body cholesterol except that in nervous tissue (22); its size can be swelled by decreasing its excretion, increasing its synthesis, or increasing the absorption of exogenous cholesterol. After a change in regimen c, a decreased slope in the specific activity-time curve is due to decreased endogenous synthesis or increased pool size; increased slope is due to increased synthesis or decreased pool size.

stand alone for many of the purposes discussed in this report. However, for experiments in which it is necessary to distinguish between endogenous and exogenous cholesterol in the feces, an isotopic technique, in which isotopic equilibrium is attained among all readily miscible pools of cholesterol, must be employed along with the GLC method. Chevallier (20) and Wilson (21) have taken advantage of these considerations in their studies of sterol balances in rats in the isotopic steady state. However, the isotopic method as presently employed cannot stand alone, since it gives no measure of the degree of sterol degradation during intestinal transit; fortunately, such losses can be corrected by employing the GLC method. Thus, in many experimental situations the two methods are complementary.

Reciprocal changes in plasma cholesterol and fecal steroid excretion. When corn oil replaced butter oil in the diet of this patient, the plasma cholesterol content decreased by an estimated total of $5,450 \mathrm{mg}$, whereas total fecal steroid excretion increased by $18,192 \mathrm{mg}$; the increase was about equally divided between acidic and neutral steroids of endogenous origin. However, it is important to emphasize that the increased fecal steroid output was not confined in time to the transitional period (II) when plasma cholesterol concentrations were decreasing, but persisted through most of the 24-day period that corn oil constituted the sole dietary fat (Figure 3). The 1957 study in this patient (1) was similarly designed, and the first stool analyses were made 6 weeks after intravenous administration of cholesterol-4- ${ }^{14} \mathrm{C}$. Fecal steroid analyses were made solely by the isotopic method, without corrections for fecal flow or for sterol degradation. A large increase in fecal neutral steroids (but not bile acids) was noted in the 14-day transitional period (II) when corn oil replaced butter in the diet, whereas in the present study there was a considerable overlap of increased fecal steroid excretion from period II into period III, and both steroid fractions were equally affected; we have no explanation for the differences in distribution and duration of the increased steroid excretion at the two times.

The variability of the excretion data obtained by both methods deserves special comment: As Figure 3 suggests, a statistically significant difference between periods I and II + III depends on having data from a sizable number of stool collection periods before and after the dietary fat exchange.

It was suggested on the basis of the previous study (1) that the alterations in plasma cholesterol content caused by exchanges of dietary fats could be explained by reciprocal changes in intestinal excretion of steroids. Numerous reports published since 1957 claim to have shown that unsaturated fats induce increased excretions of bile acids, neutral steroids, or both, but as previously discussed (7-9) we have serious reservations about many of these results because of inadequate methods. Indeed, in view of our recent finding that sterol degradation of considerable magnitude can occur (up to $60 \%$ of the plant sterols ingested were degraded in one patient), we believe that all previous studies of sterol balance as a function of exchange of dietary fat, including our own (9), must be viewed with some suspicion. This is the only patient out of 11 studied here in whom an increased excretion of fecal neutral steroids has resulted from the feeding of unsaturated fat. Until such studies have been repeated numerous times, with varying sterol intakes and with adequate corrections for sterol degradation during intestinal 
transit, it seems unwise to attempt to lay down general rules about the mechanism of the effect of unsaturated dietary fats on serum cholesterol concentrations.

In the present study we have shown that the increment in excretion of fecal steroids was greater than the decrement in plasma cholesterol content when corn oil replaced butter in the diet. That this increase in fecal steroids was not due to increased cholesterol synthesis is evident from the slope of the cholesterol- ${ }^{14} \mathrm{C}$ specific activity-time curve in Figure 4 ; if there had been increased synthesis, a downward break in the curve would have been seen, as schematized in Figure 5. There was, in fact, a slight temporary upward deflection in the curve during period II that could have been caused either by a temporary curtailment of cholesterol synthesis or by abrupt cessation of absorption of unlabeled dietary cholesterol after its deletion from the diet in period II. Since the data plotted in Figure 4 indicate that the increment in fecal steroids could not have been caused by increased cholesterol synthesis, and since the increment was three times as large as the plasma cholesterol decrement, we conclude that there had been a net flux of cholesterol out of tissues other than plasma. Whether this flux had truly ended on day 60 (Figure 3), and which tissues can so readily release cholesterol, are subjects for future experiments to determine. Neither can we say whether the flux observed was caused by the type of fatty acids in corn oil or by its plant sterol content, in view of the unequal intakes of cholesterol and plant sterols in the two diets. The present experiment was designed primarily to compare two methods for carrying out sterol balance studies and not as an exploration of the mechanisms responsible for the cholesterol-lowering properties of corn oil.

Absorption. The absorption of exogenous cholesterol in man cannot be measured as a straightforward difference between cholesterol intake and fecal sterol output because of the contribution of endogenously synthesized cholesterol to the enterohepatic pool. The studies of Stanley and Cheng (22) and Karvinen, Lin, and Ivy (23) represent efforts to solve this difficulty by ingenious use of orally administered internal standards. Kaplan, Cox, and Taylor (24) investigated this question in 24 healthy volunteers by feeding a constant amount of labeled cholesterol each day, diluted with various amounts of unlabeled cholesterol; they measured the specific activity of plasma cholesterol over many weeks and calculated that the absorption maximum might be as low as 150 to 300 mg per day. Wilson and Lindsey (25) measured the absorption of fed cholesterol by calculations based on the specific activity of plasma cholesterol and fecal neutral sterols in two normal men fed small doses of radioactive cholesterol daily until isotopic equilibrium had been attained. They found that cholesterol absorption was small, even when the intake was very large: $300 \mathrm{mg}$ absorbed from an intake of $3 \mathrm{~g}$. We also have noted the same limitation of cholesterol absorption in somewhat similar unpublished studies of two hypercholesteremic females. In the present study we have presented still another method for calculating cholesterol absorption, by measuring the unabsorbed dietary cholesterol as the difference between the excretion of fecal neutral steroids determined by the two techniques used in this study. With an intake of $300 \mathrm{mg}$ per day, the absorption in five consecutive 8 -day periods averaged $36 \%$, or only $108 \mathrm{mg}$ per day.

In the future, studies of different cholesterol intakes in the same patient must be made to determine the various factors that affect this absorption in normal and abnormal states.

\section{Summary}

A cholesterol balance study was undertaken in a 50-year-old male with hypercholesteremia and carbohydrate-induced hyperglyceridemia in order to compare two independent, simultaneously applied methods for measuring this balance: the isotopic balance method and a new method depending on chemical isolation and gas liquid chromatographic analysis. After intravenous administration of cholesterol-4- ${ }^{14} \mathrm{C}$, isotopic equilibrium between plasma and tissue cholesterol pools was reached only after 35 days.

After 35 days the results obtained by the isotopic balance method represented the excretion of steroids of endogenous origin. Earlier than this the results obtained by this method for fecal acidic steroids were falsely high. On the other hand, the chemical isolation method gave valid results for fecal acidic steroids throughout the experiment. 
Fecal neutral steroids measured by the isotopic balance method accurately estimated neutral steroids of endogenous origin, whereas the chemical isolation method measured this plus unabsorbed dietary sterols. Absorption of cholesterol was calculated from the difference between the results for neutral steroid excretion obtained by the two balance methods : $108 \mathrm{mg}$ was absorbed per day from an intake of $300 \mathrm{mg}$ per day.

The increment in total fecal steroids, when corn oil replaced butter in the diet, was three times larger than the decrement in plasma cholesterol; the acidic and neutral steroids of endogenous origin shared equally in that increment. Since cholesterol biosynthesis was not increased, the excretion results strongly suggest a net flux of cholesterol out of tissues.

The data presented in this study lend strong support to the validity of our chemical isolation method, which quantifies the end products of cholesterol metabolism by thin layer and gas liquid chromatography and which also permits appropriate corrections for sterol degradation occurring during intestinal transit. Further, the usefulness is demonstrated of using the two balance methods simultaneously.

\section{Acknowledgments}

We are grateful to Miss Mary Nahon, Miss Nancy Yule, and Mrs. Marilyn Aguirre for their excellent technical assistance.

\section{References}

1. Hellman, L., R. S. Rosenfeld, W. Insull, Jr., and E. H. Ahrens, Jr. Intestinal excretion of cholesterol: a mechanism for regulation of plasma levels (abstract). J. clin. Invest. 1957, 36, 898.

2. Lindstedt, S., and E. H. Ahrens, Jr. Conversion of cholesterol to bile acids in man. Proc. Soc. exp. Biol. (N. Y.) 1961, 108, 286.

3. Ahrens, E. H., Jr., J. Hirsch, K. Oette, J. W. Farquhar, and $Y$. Stein. Carbohydrate-induced and fat-induced lipemia. Trans. Ass. Amer. Phycns 1961, 74, 134.

4. Knittle, J. L., and E. H. Ahrens, Jr. Carbohydrate metabolism in two forms of hyperglyceridemia. J. clin. Invest. 1964, 43, 485.

5. Moore, R. B., J. T. Anderson, A. Keys, and I. D. Frantz, Jr. Effect of dietary fat on fecal excretion of cholesterol and its degradation products in human subjects (abstract). J. Lab. clin. Med. 1962, 60, 1000.
6. Avigan, J., and D. Steinberg. Sterol and bile acid excretion in man and the effects of dietary fat. J. clin. Invest. 1965, 44, 1845.

7. Grundy, S. M., E. H. Ahrens, Jr., and T. A. Miettinen. Quantitative isolation and gas-liquid chromatographic analysis of total fecal bile acids. J. Lipid Res. 1965, 6, 397.

8. Miettinen, T. A., E. H. Ahrens, Jr., and S. M. Grundy. Quantitative isolation and gas-liquid chromatographic analysis of total dietary and fecal neutral steroids. J. Lipid Res. 1965, 6, 411.

9. Spritz, N., E. H. Ahrens, Jr., and S. Grundy. Sterol balance in man as plasma cholesterol concentrations are altered by exchanges of dietary fats. J. clin. Invest. 1965, 44, 1482.

10. Lees, R. S., and D. S. Fredrickson. The differentiation of exogenous and endogenous hyperlipemia by paper electrophoresis. J. clin. Invest. 1965, 44, 1968.

11. Ahrens, E. H., Jr., V. P. Dole, and D. H. Blankenhorn. The use of orally-fed liquid formulas in metabolic studies. Amer. J. clin. Nutr. 1954, 2, 336.

12. Abell, L. L., B. B. Levy, B. B. Brodie, and F. E. Kendall. A simplified method for the estimation of total cholesterol in serum and demonstration of its specificity. J. biol. Chem. 1952, 195, 357.

13. Whitby, L. G., and D. Lang. Experience with the chromic oxide method of fecal marking in metabolic balance investigations on humans. J. clin. Invest. 1960, 39, 854.

14. Stanley, M. M., and S. H. Cheng. Excretion from the gut and gastrointestinal exchange studied by means of the inert indicator method. Amer. J. dig. Dis. 1957, 2, 628.

15. Gould, R. G., L. V. Lotz, and E. M. Lilly. Absorption and metabolism of dihydrocholesterol and beta-sitosterol in Biochemical Problems of Lipids, Proceedings of the Second International Conference, Ghent, Belgium, 1955, G. Popják and E. L'eBreton, Eds. London, Butterworths, 1956, p. 353.

16. Zilversmit, D. B. The design and analysis of isotope experiments. Amer. J. Med. 1960, 29, 832.

17. Edelman, I. S., and J. Leibman. Anatomy of body water and electrolytes. Amer. J. Med. 1959, 27, 256.

18. Chobanian, A. V., and W. Hollander. Body cholesterol metabolism in man. I. The equilibration of serum and tissue cholesterol. J. clin. Invest. 1962, 41, 1732.

19. Chobanian, A. V., B. A. Burrows, and W. Hollander. Body cholesterol metabolism in man. II. Measurement of the body cholesterol miscible pool and turnover rate. J. clin. Invest. 1962, 41, 1738.

20. Chevallier, F. Etude des origines des stérols fécaux du rat a l'aide d'indicateurs nucléaires. III. Influence de la concentration du cholestérol alimen- 
taire sur les quantités de cholestérol excrété par la bile et par la paroi intestinale. Bull. Soc. Chim. biol. (Paris) 1960, 42, 643.

21. Wilson, J. D. The quantification of cholesterol excretion and degradation in the isotopic steady state in the rat: the influence of dietary cholesterol. J. Lipid Res. 1964, 5, 409.

22. Stanley, M. M., and S. H. Cheng. Cholesterol exchange in the gastrointestinal tract in normal and abnormal subjects. Gastroenterology 1956, 30, 62.
23. Karvinen, E., T. M. Lin, and A. C. Ivy. Capacity of human intestine to absorb exogenous cholesterol. J. appl. Physiol. 1957, 11, 143.

24. Kaplan, J. A., G. E. Cox, and C. B. Taylor. Cholesterol metabolism in man. Studies on absorption. Arch. Path. 1963, 76, 359.

25. Wilson, J. D., and C. H. Lindsey, Jr. Studies on the influence of dietary cholesterol on cholesterol metabolism in the isotopic steady state in man. J. clin. Invest. 1965, 44, 1805. 